\title{
What types of powdery mildew can infect wheat-barley introgression lines?
}

\section{Aranyi, Nikolett Reka}

2014-05

Aranyi , N R, Varga , I, Poczai , P , Cernak , I , Vida , G, Molnar-Lang , M \& Hoffmann , B 2014 , ' What types of powdery mildew can infect wheat-barley introgression lines? ' , European Journal of Plant Pathology, vol. 139 , no. 1 , pp. 19-25 . https://doi.org/10.1007/s10658-014-0382-0

http://hdl.handle.net/10138/324959

https://doi.org/10.1007/s10658-014-0382-0

publishedVersion

Downloaded from Helda, University of Helsinki institutional repository.

This is an electronic reprint of the original article.

This reprint may differ from the original in pagination and typographic detail.

Please cite the original version. 


\section{What types of powdery mildew can infect wheat-barley introgression lines?}

\author{
Nikolett Réka Aranyi • Ildikó Varga • Péter Poczai • \\ István Cernák • Gyula Vida • Márta Molnár-Láng • \\ Borbála Hoffmann
}

Accepted: 2 January 2014 / Published online: 21 January 2014

(C) KNPV 2014 internal transcribed spacer sequences (rDNA-ITS). We identified Blumeria graminis f.sp. tritici isolate 14 (HM484334) on the wheat parent and all wheat-barley introgression lines and $B$. g. f. sp. hordei isolate MUMH1723 (AB 273556) on the barley parent, respectively. The wheat-barley introgression lines were inoculated with barley powdery mildew under greenhouse conditions. According to our results the added barley chromosomes (or segments) do not cause host range expansion of barley powdery mildew.

Keywords Wheat-barley introgression lines · Formae speciales of powdery mildew $\cdot$ Host range expansion

Powdery mildew caused by Blumeria graminis (DC.) Speer, is a major problem in cereal production around the world. This obligate biotrophic fungus can reduce the quality and quantity of cereal yields. It has developed eight distinct formae speciales (f.sp.) so far, which show strict host specialization (Inuma et al. 2007); for example, Triticum spp. and Hordeum spp. are appropriate hosts to B.graminis f.sp. tritici and f.sp. hordei, respectively. The evolution of the ability to exploit a novel host in addition to the host of origin is called host range expansion (Giraud et al. 2010). It is expected to occur rather frequently, as only a few modifications in the effector repertoire of the pathogen can enable it to adapt to a closely related plant species (Schulze-Lefert and Panstruga 2011; Troch et al. 2012). This is especially true for wheat and barley, the two important cereal crops worldwide, where the host-pathogen interactions 
are well known. Interestingly only a few studies deal with the host range expansion of cereal powdery mildew, however, intergeneric hybridization between wheat and barley (Triticum aestivum L. $\times$ Hordeum vulgare L.) could result in the host range expansion of barley powdery mildew. The introgression of barley chromosomes or chromosome segments into the wheat genome may result in the transfer of useful traits from barley to wheat, e.g., tolerance to drought and soil salinity, earliness, or various traits for specific nutritional quality. Since the first successful hybridization between wheat and barley (Kruse 1973) only a few wheat-barley addition, substitution and translocation lines have been developed (Islam and Shepherd 1992; Koba et al. 1997; Molnár-Láng et al. 2000a, b; 2012). Scarce information is available on the ability of barley chromosomes to compensate for wheat chromosomes regarding important agronomical characteristics (Hoffmann et al. 2011). But together with beneficial traits sensitivity to specialized pathogens is also transferred?

In this study we investigated whether barley powdery mildew can infect the hybrids originating from wheatbarley crosses. The objectives of this study were to: 1) to identify the powdery mildew symptoms on introgression lines under natural infection on the field; 2) to collect the infected leaves from the field and identify the fungus formae speciales by ribosomal internal transcribed spacer sequences (rDNA-ITS) regions; and 3) to test the seedling plants in accordance with the behaviour towards barley powdery mildew infection after artificial infection under greenhouse conditions.
Different wheat-barley addition, substitution, translocation lines as well as parent lines (Table 1) were examined in this study. The experiments included greenhouse and field infections. The field experiment was performed during the 2011-2012 growing seasons at UP Georgikon Faculty, Keszthely. The soil of the experimental site is a lessivated brown forest soil (FAO: Luvic phaosem) with low organic material, medium Kand $\mathrm{P}$ content. Row space was $30 \mathrm{~cm}$. Each genotype was sown in a $15 \mathrm{~m}$ long row. The 2011-2012 wheat season was characterized by a spring and summer drought. Irrigation and high plant density helped in making the microclimate more favourable for the development of the disease.

Disease symptoms were visually recorded on the leaves, on different occasions (from booting, Zadoks scale [ZAD] 40 to early maturity, ZAD 80 ). The plants were in different developmental stages at a given time. We used the Saari and Prescott's severity scale (0-9) to assess wheat foliar diseases (Saari and Prescott 1975). The percentage of the infected leaf area was evaluated for the whole plant and for the flag-leaf.

Heavily infected leaves were collected from the field, from all genotypes (except $6 \mathrm{H}$ addition line, which genotype was not infected). Eleven chasmotecium were isolated from infected spots of each line. Total genomic DNA was extracted from chasmothecia using the Phire Plant Direct PCR Kit (Thermo Fisher Scientific, USA). For PCR amplifications tissue-direct technique was used requiring very little sample material compared to other alternative methods. The direct PCR (diPCR)

Table 1 The plant material examined in this study. The introgression lines and Mv9 kr1 wheat line were developed at the Department of Plant Genetic Resources and Organic Breeding, Centre for Agricultural research, Hungarian Academy of Sciences

\begin{tabular}{|c|c|c|c|}
\hline Species & Cultivar or line & Pedigree & References \\
\hline Wheat & Mv9 kr1 & Chinese Spring $\times$ Martonvásári 9 & $\begin{array}{l}\text { Molnár-Láng } \\
\text { et al. } 1996\end{array}$ \\
\hline \multirow[t]{9}{*}{ Wheat-barley hybrids } & $2 \mathrm{H}$ addition & Mv9 kr1 × Igri & \multirow{3}{*}{$\begin{array}{l}\text { Molnár-Láng et al. 2000a; } \\
\text { Szakács and Molnár-Láng } 2007\end{array}$} \\
\hline & $3 \mathrm{H}$ addition & Mv9 kr1 × Igri & \\
\hline & $4 \mathrm{H}$ addition & Mv9 kr1 × Igri & \\
\hline & $6 \mathrm{H}$ addition & $($ Chinese Spring $\times$ Betzes $) \times$ Mv9kr1 & Molnár-Láng et al. 2000a \\
\hline & $6 \mathrm{HS}$ addition & Mv9 kr1 $\times$ Igri & \multirow[t]{2}{*}{ Szakács and Molnár-Láng 2010} \\
\hline & $7 \mathrm{H}$ addition & Mv9 kr1 $\times$ Igri & \\
\hline & 4H (4D) substitution & $($ Chinese Spring $\times$ Betzes $) \times$ Mv9kr1 & Molnár et al. 2007 \\
\hline & $\begin{array}{l}\text { 3BL.3HS translocation } \\
6 \mathrm{~B}-4 \mathrm{H} \text { translocation }\end{array}$ & $\begin{array}{l}(\text { Chinese Spring } \times \text { Betzes }) \times \text { Mv9kr1 } \\
(\text { Chinese Spring } \times \text { Betzes }) \times \text { Mv9kr1 }\end{array}$ & \multirow[t]{2}{*}{ Molnár-Láng et al. 2000b } \\
\hline & 7D-5HS translocation & Mv9 kr1 × Igri & \\
\hline Barley & Igri & - & - \\
\hline
\end{tabular}


Table 2 Referred Blumeria graminis isolates in this study with sequences database accession numbers

\begin{tabular}{lllc}
\hline Host of sampling isolates & Origin host of isolates in database & $\begin{array}{l}\text { Database Accession } \\
\text { No. }\end{array}$ & Refences \\
\hline Triticum aestivum & Triticum aestivum (isolate: 14) & HM484334 & Walker et al. \\
& & HM484334 & Walker et al. \\
$\begin{array}{l}\text { Triticum aestivum } \text { L. } \times \text { Hordeum vulgare introgression } \\
\text { lines }\end{array}$ & Triticum aestivum (isolate: 14) & AB273556 & Inuma et al. \\
$\begin{array}{l}\text { Hordeum vulgare } \\
\text { Hordeum distichum (isolate: }\end{array}$ & MUMH1723) & 2007 \\
\hline
\end{tabular}

amplification was performed with the primers ITS1 and ITS4 described by White et al. (1990). Amplification reactions were performed in $20 \mu \mathrm{l}$ total volume PCR reaction containing $8.6 \mu \mathrm{l}$ nuclease-free water, $\sim 20 \mathrm{ng}$ template DNA, $0.2 \mu \mathrm{M}$ ITS1 and ITS4 primer, $0.2 \mathrm{mM}$ dNTP, $10 \mu$ PCR buffer $(1 \mathrm{mM}$ Tris/HCl, $\mathrm{pH} 8.8$ at $25^{\circ} \mathrm{C}, 1.5 \mathrm{mM} \mathrm{MgCl} 2,50 \mathrm{mMKCl}$ and $0.1 \%$ Triton $\mathrm{X}-100)$ and $0.4 \mu \mathrm{l}$ Phire Hot Start II DNA Polymerase (Thermo Fisher Scientific, USA). PCR was performed using $5 \mathrm{~min}$ at $98^{\circ} \mathrm{C}$ for initial denaturation, 40 cycles of $20 \mathrm{~s}$ denaturation at $98^{\circ} \mathrm{C}, 1 \mathrm{~min}$ annealing at $53^{\circ} \mathrm{C}$, and 2 min extension at $72^{\circ} \mathrm{C}$, followed by a final extension for $5 \mathrm{~min}$ at $72^{\circ} \mathrm{C}$. Amplification products were separated at $1.5 \%$ agarose gels stained with ethidium-bromide. PCR fragments excised from agarose gels were cleaned by removing non-incorporated primers with $10 \mathrm{U}$ exonuclease I and degradation of nucleotides by $1 \mathrm{U}$ thermosensitive alkaline phosphatase (Exo I and FastAP, Fermantas, Lithuania). PCR mixes were incubated at $37^{\circ} \mathrm{C}$ for $15 \mathrm{~min}$ and the reaction was stopped by heating the mixture at $85^{\circ} \mathrm{C}$ for $15 \mathrm{~min}$. Sequencing was performed on an ABI 3130XL automated sequencer in both directions using the ITS1 and ITS4 primers and the ABI PRISM BigDye Terminator Cycle Sequencing Ready Reaction Kit v.3.0. All sequences were annotated and deposited in GenBank (Benson et al. 2011); accession numbers are given in Table 2.

Forward and reverse sequence reads for all isolates were assembled with CodonCode Aligner v.3.7.1. (codoncode.org). Discrepancies were manually

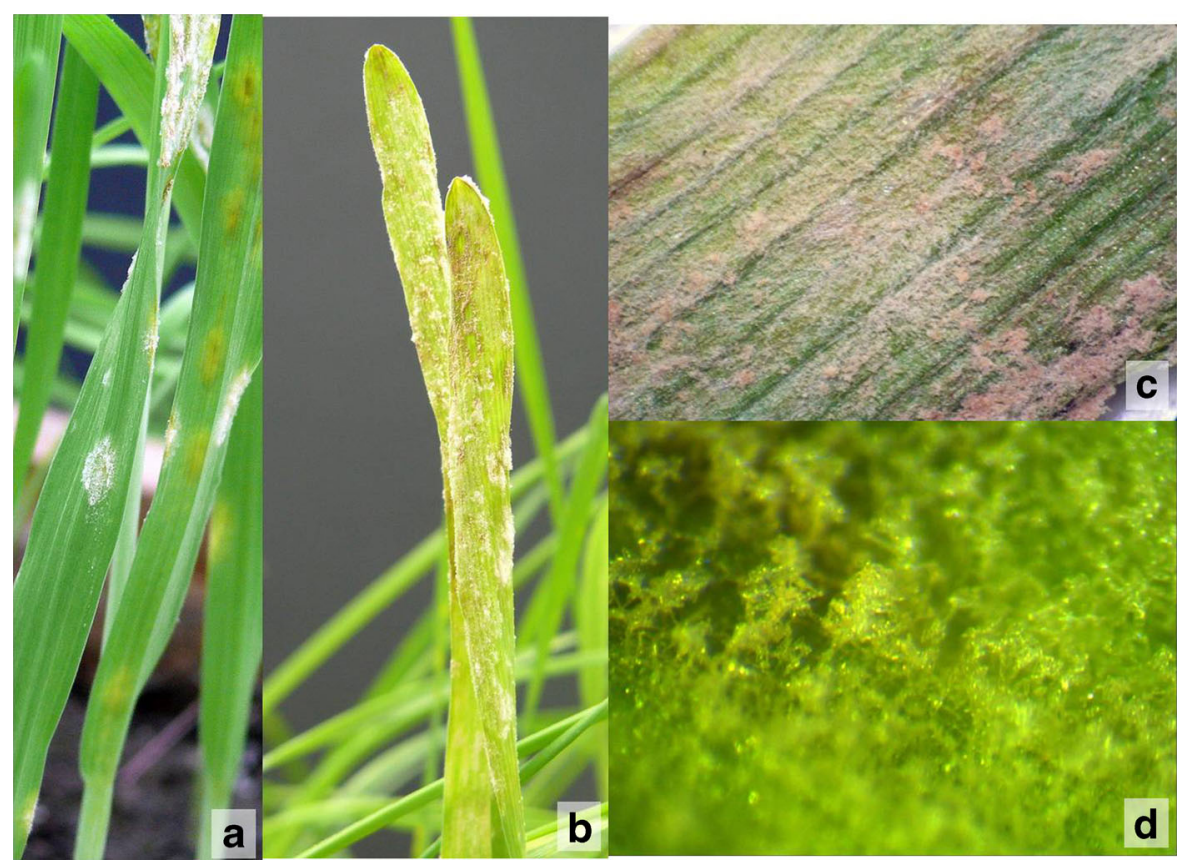

Fig. 1 Symptoms of Blumeria graminis f.sp. hordei isolate A6 (a) and BP (b) on leaves of 'Igri' barley parent. Mycelium of isolate BP under stereo microscope, with $15 \times(\mathbf{c})$ and $70 \times(\mathbf{d})$ magnification 


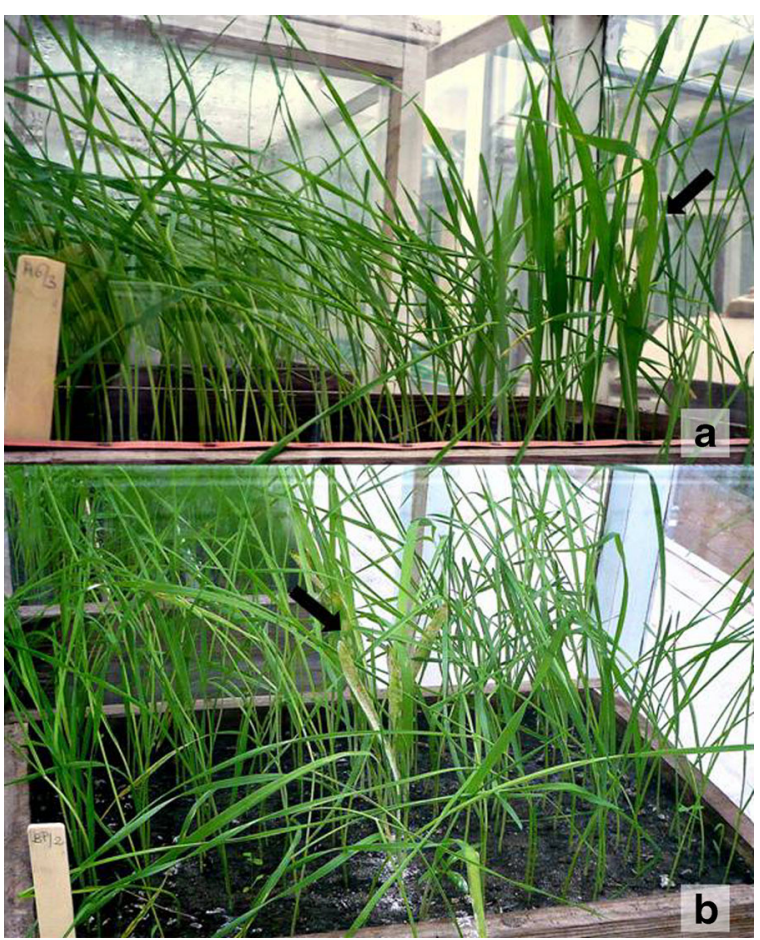

Fig. 2 Testing of wheat- barley hybrids and their parent lines in isolated glass box in greenhouse with Blumeria graminis, f.sp. hordei isolates. Both isolates A6 (a) and BP (b) infected the 'Igri' barley parent (arrows), but no symptoms were emerged on the introgression lines and 'Mv9kr1' wheat parent resolved by editing the traces using the compare option of the advanced assembly function. Single consensus sequences were extracted in FASTA format from the compared assemblies. Multiple sequence assemblages were aligned with MUSCLE (Edgar 2004) as implemented in Geneious v.4.8.5 (geneious.com) using default settings. Ribosomal exons and spacer regions were annotated in the alignments using the fungal reference sequences deposited in the ITS2 database (Koetschan et al. 2010). Obtained sequences were compared with sequences available in GenBank database using the basic local alignment search tool (blastn) with default parameters.

Blumeria graminis f.sp. hordei A6 (Wiberg 1974) and BP (Hungarian isolate, El-Zahaby et al. 1995) isolates obtained from the Plant Protection Institute, Centre for Agricultural Research, were used for inoculation. The isolates were formerly tested and propagated on 'Igri' barley parent genotype in an isolated glass box in greenhouse. Ten plants of each genotype were grown in $50 \times 40 \mathrm{~cm}$ wooden boxes under isolator with $16 \mathrm{~h}$ daily natural and illuminated light conditions at $18{ }^{\circ} \mathrm{C}$. The relative humidity in the isolator box was $80-90 \%$. The genotypes were completely randomised. Infection was carried out on 10-day-old seedlings in three replications per isolate. Leaves with heavily sporulating

Table 3 Assessment of severity of powdery mildew infection on the introgression lines and their parent cultivars

\begin{tabular}{|c|c|c|c|c|c|c|c|c|c|}
\hline \multirow[t]{2}{*}{ Genotype } & \multicolumn{2}{|c|}{4 May 2012} & \multicolumn{2}{|c|}{9 May 2012} & \multicolumn{2}{|c|}{18 May 2012} & \multicolumn{3}{|c|}{3 June 2012} \\
\hline & $\mathrm{IA}, \%$ & S.\& P. scale & IA, $\%$ & S.\& P. scale & $\mathrm{IA}, \%$ & S.\& P. scale & $\mathrm{IA}, \%$ & S.\& P. scale & IA flag-leaf, $\%$ \\
\hline $2 \mathrm{H}$ add. & 30 & 6 & 40 & 6 & 50 & 6 & 50 & 7 & 5 \\
\hline $3 \mathrm{H}$ add. & 20 & 5 & 30 & 7 & 40 & 7 & 50 & 8 & 40 \\
\hline $4 \mathrm{H}$ add. & 40 & 7 & 40 & 7 & 60 & 7 & 70 & 8 & 80 \\
\hline $6 \mathrm{H}$ add. & $<5$ & 1 & $<5$ & 1 & $<$ & 1 & $<5$ & 1 & 0 \\
\hline $6 \mathrm{HS}$ add. & 10 & 4 & 20 & 6 & 20 & 6 & 30 & 7 & 5 \\
\hline 7H add. & 20 & 4 & 20 & 6 & 20 & 6 & 30 & 7 & 5 \\
\hline 7D-5HS transl. & 10 & 4 & 20 & 6 & 20 & 6 & 30 & 7 & 5 \\
\hline 6B-4H transl. & 10 & 4 & 20 & 6 & 20 & 6 & 30 & 7 & 5 \\
\hline 3HS.3BL transl. & 40 & 7 & 40 & 7 & 50 & 7 & 50 & 8 & 40 \\
\hline 4H (4D) subst. & 10 & 3 & 10 & 3 & 20 & 6 & 20 & 7 & 5 \\
\hline Mv9kr1 wheat & 40 & 5 & 40 & 6 & 50 & 6 & 60 & 8 & 60 \\
\hline Igri barley & 10 & 4 & 10 & 4 & 20 & 6 & 30 & 8 & 80 \\
\hline
\end{tabular}

IA = percentage of infected area evaluated for the whole plant; S.\& P. scale=Saari and Prescott's severity scale, 0 to 9 scale, ranging from no visible symptoms (0) to visible symptoms on spike (9); IA flag-leaf=percentage of infected flag-leaf area

Mv9kr1 $\times$ Igri: $2 \mathrm{H}, 3 \mathrm{H}, 4 \mathrm{H}, 6 \mathrm{HS}, 7 \mathrm{H}$ addition, $7 \mathrm{D}-5 \mathrm{HS}$ translocation lines;

(Chinese Spring $\times$ Betzes $) \times$ Mv9kr: 4H (4D) substitution, 3HS.3BL, 6B-4H translocation lines 
colonies were shaken in the test box. The presence of powdery mildew on the seedlings was scored on the 10th day after inoculation.

Blumeria graminis f.sp. hordei isolates A6 and BP infected the 'Igri' barley parent, and they heavily sporulated under artificially infected conditions (Fig. 1). On the contrary, the introgression lines and 'Mv9krl' wheat parent were not infected by B.g. f.sp. hordei (Fig. 2).

Powdery mildew symptoms were observed on all genotypes in the field (Table 3; Fig. 3). 'Mv9kr1' wheat parent and $4 \mathrm{H}$ addition line were highly susceptible to the disease (infected leaf area $60 \%$ and $70 \%$, respectively). The highest percentage of infected flag-leaf area was recorded for these genotypes and for 'Igri' barley parent. On the leaves of $6 \mathrm{H}$ addition line no symptoms were observed just few mycelium sporadically on the stem and only $5 \%$ of flag-leafs were infected in case of most of the examined lines: 4H (4D) subs.; 6HS add.;
7H add.; 7D-5HS transl.; 6B-4H transl.; 2H add., while in case of the wheat parental genotype $60 \%$ of the flagleaf area was infected.

Direct PCR amplifications yielded one $562 \mathrm{bp}$ size band (Fig. 4) with no length variation indicating lack of alternative ITS copies amplifying from paralogous loci. Using the primers of White et al. (1990) we detected only fungal ITS sequences and sequencing revealed no traces of plant contamination. We found no variation among the sequenced isolates and natural infection was most probably caused by the same haplotype. The BLAST search carried showed a $100 \%$ match on entry from Blumeria graminis f. sp. tritici isolate 14 (HM484334) deposited by Walker et al. (2011) and Blumeria graminis f. sp. hordei isolate MUMH1723 (AB 273556) deposited by Inuma et al. (2007). Blumeria graminis f. sp. tritici
Fig. 3 Symptoms of Blumeria graminis f.sp. tritici isolate on leaves of " $4 \mathrm{H}$ addition lines on the field (a). Mycelia and conidia (b) of Bgt. (stereo microscope photo, enlargement: $15 \times$ ). Disease symptoms on flag-leaves $(\mathbf{c}) . \mathrm{A}=$ 4H (4D) substitution; $\mathrm{B}=2 \mathrm{H}, \mathrm{C}=$ $3 \mathrm{H}, \mathrm{D}=4 \mathrm{H}, \mathrm{E}=7 \mathrm{H}, \mathrm{F}=6 \mathrm{HS}$ addition; $\mathrm{G}=3 \mathrm{BL} .3 \mathrm{HS}, \mathrm{H}=6 \mathrm{~B}-$ 4H, I=7D-5HS translocation; $\mathrm{J}=$ Mv9kr1; K=Igri

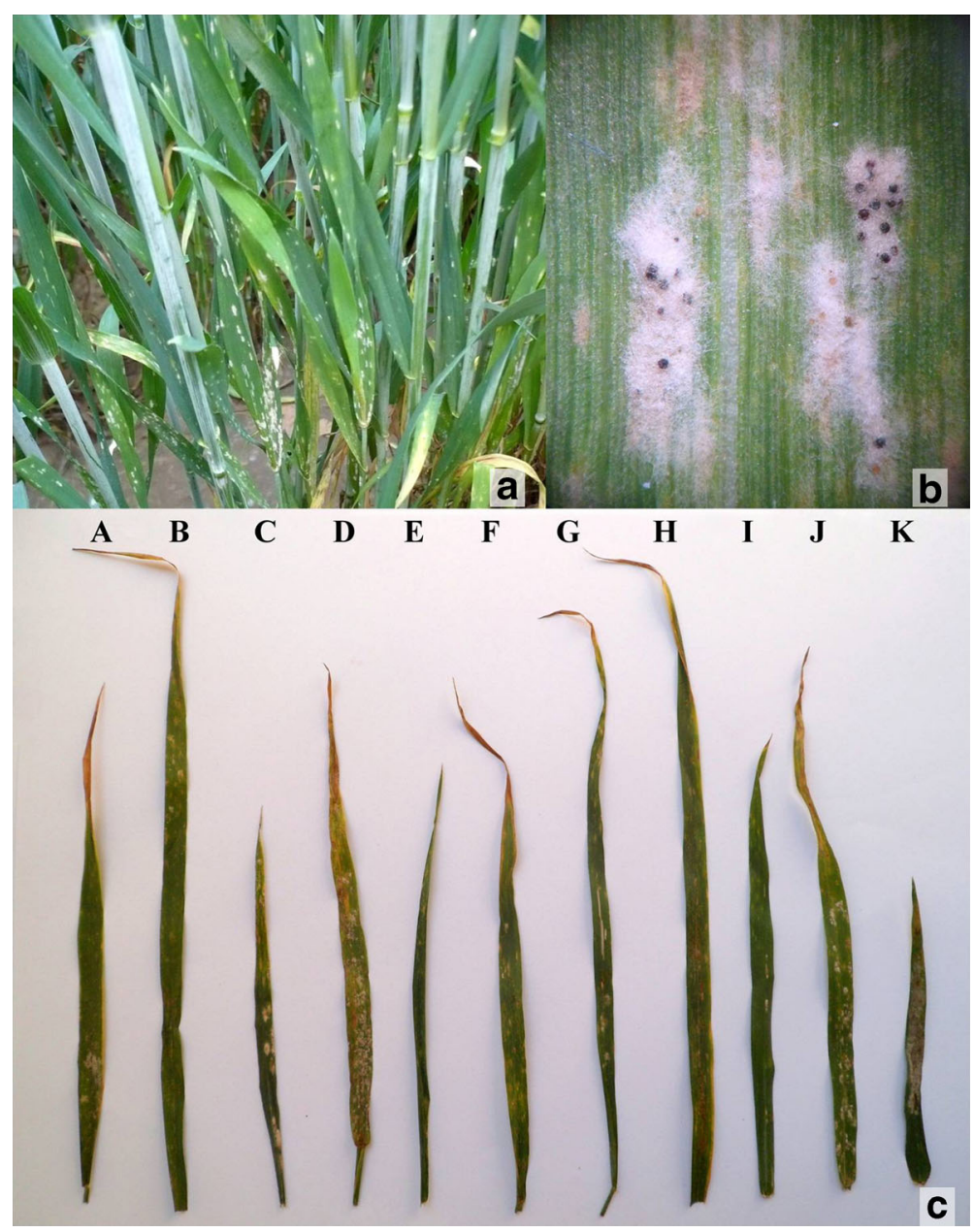




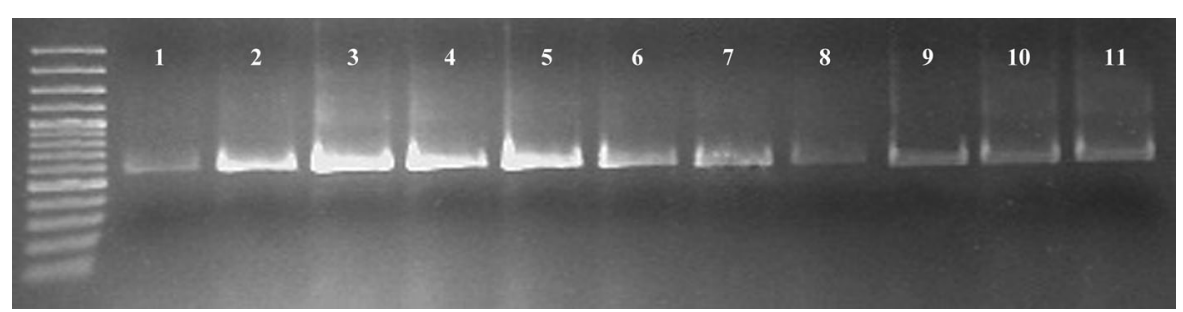

Fig. 4 PCR amplification patterns of the nuclear ribosomal internal transcribed spacer (rDNA ITS) region among isolates, showing one clear 562 bp size fragment excised and used for sequencing; indicating that the identification of isolates was based on

pathotype was identified exclusively on the wheat parent and wheat-barley hybrids, while Blumeria graminis f. sp. hordei pathotype was collected only from Igri barley parent.

The present study reveals that Blumeria graminis f.sp. hordei is currently unable to infect wheat-barley introgression lines. However, our research demonstrated that $B . g$. f.sp. tritici is able to infect these lines. Wheatbarley introgression lines had different susceptibility to B. g. f.sp. tritici isolate 14, nonetheless ' $\mathrm{Mv} 9 \mathrm{kr} 1$ ' wheat parent showed strong susceptibility to this disease. Based on our results we identified $B . g$. f. sp. hordei isolate MUMH1723 (AB 273556) on the barley parent (Table 3). This isolate described by Inuma et al. (2007) was collected in Iran.

According to our results the added barley chromosomes (segments) by themselves do not affect host range expansion of barley powdery mildew. A lot of studies discuss the powdery mildew-host interaction, however only a few deal with powdery mildew host range expansion that can occur as a consequence of interspecies hybridization. The most important intergeneric hybrid is triticale $(\times$ Triticosecale Wittmack) with rising production area and importance. With the expansion of the triticale production area, powdery mildew emerged on this new host expanded from wheat to triticale multiple times at different locations in Europe (Walker et al. 2011; Troch et al. 2012; Klocke et al. 2013). Only a part of $B$. graminis f.sp. tritici isolates collected by Troch et al. (2012), were able to infect both the triticale (the new host) and the wheat cultivars (the previous host), whereas some isolates showed pathogenicity exclusively on triticale cultivars. The studied wheatbarley introgression lines have valuable agronomic traits, such as tolerance for drought, earliness, and high root- shoot ratio (Hoffmann et al. 2011). These orthologous ribotypes. Samples: $1=7 \mathrm{D}-5 \mathrm{HS}$ transl.; $2=3 \mathrm{H}$ add.; $3=4 \mathrm{H}$ (4D) subs.; $4=2 \mathrm{H}$ add.; $5=7 \mathrm{H}$ add.; $6=6 \mathrm{HS}$ add.; $7=$ Igri barley; $8=4 \mathrm{H}$ add.; $9=\mathrm{Mv} 9 \mathrm{kr} 1$ wheat; $10=3 \mathrm{HS} .3 \mathrm{BL}$ transl.; $11=$ $6 \mathrm{~B}-4 \mathrm{H}$ transl

advantageous traits can result in the spread of certain barley chromosomes (segments) in breeding material - as was the case with 1BL.1RS translocation (Hoffmann 2008; Köszegi et al. 2000; Singh et al. 1998), which may result in a growing selection pressure. That is why we need to investigate the possibility of host range expansion.

According to our results the added barley chromosomes (or segments) did not cause host range expansion of barley powdery mildew up to now, on the contrary: wheat powdery mildew infection was reduced in most of the examined genotypes. These results raise hopes that the introgression of barley chromosomes into the breeding material can lead to a reduction of powdery mildew susceptibility of newly bred wheat genotypes.

Acknowledgments The present publication was realized with the support of the project TÁMOP 4.2.4.A/2-11-1-2012- 0001 and TÁMOP -4.2.2. A-11/1 KONV-2012-0064. The project was realized with the support of the Hungarian Government and the European Union, with the co-funding of the European Social Fund. István Cernák is supported by the János Bolyai Research Fellowship of the Hungarian Academy of Sciences. Barley powdery mildew isolates were kindly provided by Dr. Balázs Barna, Plant Protection Institute, Centre for Agricultural Research, Hungarian Academy of Sciences, Budapest.

\section{References}

Benson, D. A., Karsch-Mizrachi, I., Lipman, D. J., Ostell, J., \& Sayers, E. W. (2011). GenBank. Nucleic Acids Research, 39, 32-37.

Edgar, R. C. (2004). MUSCLE: Multiple sequence alignment with high accuracy and high throughput. Nucleic Acids Research, 32, 1792-1797.

El-Zahaby, H. M., Gullner, G., \& Király, Z. (1995). Effects of powdery mildew infection of barley on the ascorbateglutathione cycle and other antioxidants in different host- pathogen interactions. Biochemistry and Cell Biology, $85,1225-1230$. 
Giraud, T., Gladieux, P., \& Gavrilets, S. (2010). Linking the emergence of fungal plant diseases with ecological speciation. Trends Ecology and Evolution, 25, 387-395.

Hoffmann, B. (2008). Alteration of drought tolerance of winter wheat caused by translocation of rye chromosome segment 1RS. Cereal Research Communications, 36(2), 269-278.

Hoffmann, B., Aranyi, N., \& Molnár-Láng, M. (2011). Root development and drought tolerance of wheat-barley introgression lines. Acta Biologica Szegediensis, 55(1), 81-82.

Inuma, T., Khodaparast, S. A., \& Takamatsu, S. (2007). Multilocus phylogenetic analyses within Blumeria graminis, a powdery mildew fungus of cereals. Molecular Phylogenetics and Evolution, 44, 741-751.

Islam, A. K. M. R., Shepherd, K. W. (1992). Production of wheatbarley recombinant chromosomes through induced homoeologous pairing. 1. Isolation of recombinants involving barley arms 3HL and 6HL. Theor Appl Genet, 83, 489-49.

Klocke, B., Flath, K., \& Miedaner, T. (2013). Virulence phenotypes in powdery mildew (Blumeria graminis) populations and resistance genes in triticale (x Triticosecale). European Journal of Plant Pathology, 137(3), 463-476.

Koba, T., Takumi, S., \& Shimada, T. (1997). Isolation, identification and characterization of disomic and translocated barley chromosome addition lines of common wheat. Euphytica, 96, 289-296.

Koetschan, C., Förster, F., Keller, A., Schleicher, T., Ruderisch, B., Schwarz, R., Müller, T., Wolf, M., \& Schultz, J. (2010). The ITS2 Database III - sequences and strucutres for phylogeny. Nucleic Acids Research, 38, 275-279.

Kőszegi, B., Linc, G., Juhász, A., Láng, L., \& Molnár-Láng, M. (2000). Occurence of the 1RS/1BL wheat-rye translocation in Hungarian wheat varieties. Acta Agronomica Hungarca, 48, 227-236.

Kruse, A. (1973). Hordeum - Triticum hybrids. Hereditas, 73, 157-161.

Molnár, I., Linc, G., Dulai, S. D., Nagy, E., \& Molnár-Láng, M. (2007). Ability of chromosome $4 \mathrm{H}$ to compensate for 4D in response to drought stress in a newly developed and identified wheat-barley 4H(4D) disomic substitution. Plant Breeding, 126, 369-374.

Molnár-Láng, M., Kruppa, K., Cseh, A., Bucsi, J., \& Linc, G. (2012). Identification and phenotypic description of new wheat- six-rowed winter barley disomic additions. Genome, 55(4), 302-311.

Molnár-Láng, M., Linc, G., Friebe, R. B., \& Sutka, J. (2000a). Detection of wheat-barley translocations by genomic in situ hybridization in derivatives of hybrids multiplied in vitro. Euphytica, 112(2), 117-123.

Molnár-Láng, M., Linc, G., Logojan, A., \& Sutka, J. (2000b). Production and meiotic pairing behaviour of new hybrids of winter wheat (Triticum aestivum) $\times$ winter barley (Hordeum vulgare). Genome, 43, 10451054.

Molnár-Láng, M., Linc, G., \& Sutka, J. (1996). Transfer of the recessive crossability allele $k r l$ from Chinese Spring into the winter wheat variety Martonvásári 9. Euphytica, 90, 301305.

Saari, E. E., \& Prescott, J. M. (1975). A scale for appraising the foliar intensity of wheat disease. Plant Diseases Reporter, 59, 377-380.

Schulze-Lefert, P., \& Panstruga, R. (2011). A molecular evolutionary concept connecting nonhost resistance, pathogen host range, and pathogen speciation. Trends in Plant Science, 16, $117-125$.

Singh, R. P., Huerta-Espino, J., Rajaram, S., \& Crossa, J. (1998). Agronomic effects from chromosome translocations 1BL.1RS in spring wheat. Crop Science, 38, 27-33.

Szakács, É., \& Molnár-Láng, M. (2007). Development and molecular cytogenetic identification of new winter wheat/winter barley (Martonvásári 9 kr1/Igri) disomic addition lines. Genome, 50, 43-50.

Szakács, É., \& Molnár-Láng, M. (2010). Identification of new winter wheat - winter barley addition lines (6HS and $7 \mathrm{H}$ ) using fluorescence in situ hybridization and stability of the whole 'Martonvásári 9 krl' - 'Igri' addition set. Genome, 53(1), 35-44.

Troch, V., Audenaert, K., Bekaert, B., Höfte, M., \& Haesaert, G. (2012). Phylogeography and virulence structure of the powdery mildew population on its 'new' host triticale. $B M C$ Evolutionary Biology, 12, 76.

Walker, A. S., Bouguennec, A., Confais, J., Morgant, G., \& Leroux, P. (2011). Evidence of host-range expansion from new powdery mildew (Blumeria graminis) infections of triticale $(\times$ Triticosecale) in France. Plant Pathology, 60, 207220.

White, T. J., Bruns, T., \& Lee, S. (1990). Amplification and direct sequencing of fungal ribosomal RNA genes for phylogenetics. In M. A. Innis, H. D. Gelfand, \& J. J. Sninsky (Eds.), PCR protocol: a guide to methods and applications (pp. 315-322). USA: Academic Press.

Wiberg, A. (1974). Sources of resistance to powdery mildew in barley. Hereditas, 78, 1-40. 